\title{
Computational aerodynamics in architectural siting of the structures of agro-industrial complex
}

\author{
Anton Makhinko ${ }^{1}$, and Nataliia Makhinko ,* $^{*}$ \\ ${ }^{1}$ ETUAL LLC, 1 Bortnytska, Petropavlivske, 08341, Ukraine \\ ${ }^{2}$ National Aviation University, Department of Computer Technology Construction, 1 Liubomyra Huzara Ave., Kyiv, 03058, Ukraine
}

\begin{abstract}
The article presents study of wind effect on silo parks, which was carried out by computer simulation methods. A special modeling technique was created as a software module for the Ansys Workbench platform. A finite element mesh was developed in accordance with two requirements. Through the use of this mesh, which doesn't contain needless elements which can be used for simplification of calculations and reduction of execution time, it is possible to describe the turbulent airflow in sufficient detail. The dimensions of all mesh elements are determined by special relations as the functions of the silo diameter and the Reynolds number. The major stage in this investigation was modeling of various options for flowing silos and their groups. As a result of the study, we have obtained aerodynamic characteristics of individual silos as part of silo parks and plotted charts of the distribution of pressure coefficients over the cylinder surface, changing the size of the silos, distances between them and local wind regime. Based on these data, we have drawn a conclusion about the optimal space planning locations of silos for different wind directions. Visualizations of turbulent flow around models at different speeds have also been obtained in this study.
\end{abstract}

\section{Introduction}

Construction of industrial buildings and structures requires significant resource spends. Effective use of materials is possible through rational design, construction, and operation practices, which is very important for sustainable development of modern industrial construction. One way to implement these approaches is to develop calculation methods, which must be based on accurate data. Computer simulation tools may help to obtain such data that cannot be predicted in real situations. This applies to the object of study of this article - silage parks under the influence of wind flow.

Empty cylindrical silos are very sensitive to wind loads. Their determination is performed according to normative methods [1-5]. There are also a lot of theoretical and experimental studies of these issues [610]. In general, the behavior of wind currents near the buildings of simple geometric shape is well studied [1114]. However, a lot of factors related to modern silo complexes are not taken into account. It should be noted that, first of all, the issue of mutual influence of silos in groups has not been properly examined yet. The nature of the action of the wind flow on the silo park will be different from the action on the isolated cylindrical object $[15,16]$. Strong suction forces, which are not taken into account in the classical calculation, arise between the silos. The silo can also be located in the area of wind shade from other objects. The second problem is the rough structure of the silo, as it has a corrugated wall and a large number of stiffeners. Wind exposure to such a structure causes complex wall effects, which, in its turn, will increase the load on the silo body and the roof.

Different experimental methods are often used to study such issues. However, the real blowing in the wind tunnel has a significant disadvantage, as it is impossible to reproduce the supercritical flow regime at Reynolds numbers greater than $10^{7}$. Therefore, it is advisable to use the methods of construction aerodynamics, in particular computer modelling, in order to take into account the adverse effects of wind action. In order to achieve correct results, it is necessary to take into consideration a lot of factors, such as computational mesh generation and the choice of a mathematical model of air flow turbulence, which will give consistent results. The size of this computational mesh greatly affects the accuracy of the calculation and the computation time. It ought to be noted that a highly refined mesh increases the accuracy, but complicates the calculation. The next aspect is the formulation of the simulation problem, which can be flat (2D) and three-dimensional (3D). The calculations can be performed in stationary and nonstationary formulation with different time sampling steps. It is also necessary to consider different layouts of silos in groups, which can have different sizes, locations and positions in the wind flow. The last aspect is the form of the result. Numerical aerodynamic characteristics (wind pressure coefficient, drag and lateral force), which were found for a certain wind

\footnotetext{
* Corresponding author: pasargada1985@gmail.com
} 
direction and specific position of the models, are not very informative. It is appropriate to present the results in the form of graphs, similar to building standards. Also, different computational situations for common silo configurations can be combined into an aerodynamic atlas. This form is convenient and has practical benefits.

\section{Method}

This article presents a computer simulation procedure in ANSYS CFX program for flow around the models of various cylinder configurations that schematize a silo park. Aanalysed silos, the sizes of which are most often built: from 11 meters to 30 meters. The roughness of the silo surface was taken equal to the height of the corrugation of the silo body. In general, the problem of aerodynamic calculation was considered in three versions. At first, the simplest case of a flat 2D flow was examined. The height of the computational domain was taken as one cell of the finite element mesh.

With a more complex quasi-two-dimensional flow, the height of the computational domain was taken to be equal to the two diameters of the model (silo). The last step was to perform spatial three-dimensional flow (Fig. 1).

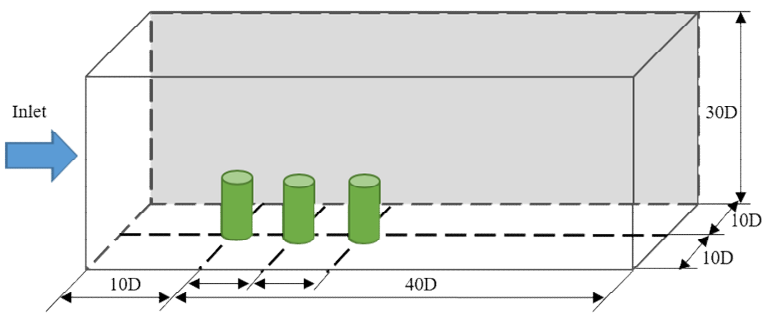

Fig. 1. 3D Geometry of the computational domain in case of three-dimensional modeling.

\subsection{Justification of the calculation}

For turbulent flows around cylindrical silos, which are characterized by wide separation zones, four mathematical models of turbulence are analyzed. These are Menter's Shear Stress Transport (SST), SlapartAllmaras Turbulence Model (SA), Large Eddy Simulation (LES) and Detached Eddy Simulation (DES). Comparison of calculations showed a discrepancy in the results up to $40 \%$ when using different turbulence models [16]. However, the most consistent results are observed between the SST and DES turbulence models, which are recommended for use in construction aerodynamics.

A parametric form was used to build a finite element mesh as well as to set the dimensions of the fluid domain in the form of a parallelepiped (Fig. 1). In such a case, the dimensions of the mesh elements will depend on the Reynolds number and on the diameter of the silo, while the dimensions of the computational domain will depend only on the diameter of the model.

At this stage, the mesh quality was checked during the simulation. For this purpose, we have taken the initial data which had already been applied in numerical or physical experiments in a wind tunnel in previous works [17-19]. Subsequently, a number of verification tests based on SST and DES turbulence models was carried out for various types of meshes.

The task was to simulate on computer flow around a cylinder in two- and three-dimensional formulation and to obtain the pressure coefficient, drag and lift force. The results were compared with experimental data [17-19]. The optimal variant of the mesh was determined not only by the solution convergence, but also by the computation time. The maximum discrepancy of the obtained data when calculating the accepted variant of the finite element mesh was up to $15 \%$.

Additionally, a comparison of wind pressure coefficients was performed for 5 points on the surface of silo body (Table 1) and for 4 points on surface of conical roof (Fig. 2). Table 1 above shows the data obtained by a full-scale field experiment in a wind tunnel [11]. Shown below are the data of the author's numerical modeling.

Table 1. Verification test results.

\begin{tabular}{|c|c|c|c|c|}
\hline \multirow{2}{*}{$\begin{array}{c}\text { Angle } \\
\beta^{\circ}\end{array}$} & \multicolumn{4}{|c|}{ Point number } \\
\cline { 2 - 5 } & 1 & 2 & 3 & 4 \\
\hline 0 & $\underline{0,87}$ & $\frac{1,0}{1,0}$ & $\frac{1,0}{1,0}$ & $\frac{0,96}{1,0}$ \\
\hline 30 & $\underline{0,30}$ & $\frac{0,20}{0,27}$ & $\underline{0,25}$ & $\underline{0,46}$ \\
\hline 70 & $\frac{-1,54}{-1,42}$ & $\frac{-1,89}{-0,96}$ & $\frac{-1,64}{-1,50}$ & $\frac{-1,15}{-1,07}$ \\
\hline 90 & $\frac{-1,96}{-2,03}$ & $\frac{-2,09}{-2,20}$ & $\frac{-1,80}{-1,69}$ & $\frac{-1,30}{-1,15}$ \\
\hline
\end{tabular}

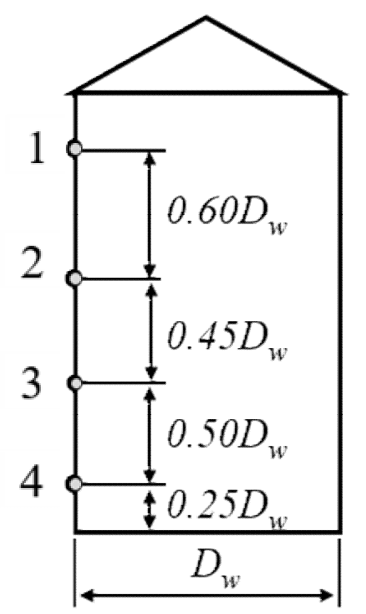

Fig. 2. Computational points on the silo surface.

\subsection{General simulation diagrams}

The main advantage of $2 \mathrm{D}$ modelling is the calculation speed. This procedure can be used for simple tasks when the silos of the same diameter are arranged in one row (Fig. 3).

Variable bench-mark data are wind speed and wind direction, the number of models, their diameter and the distance between them. The height of the silos is not taken into account in this calculation. 
In the problems on modelling, the flow velocity at the input was given in the form of the Reynolds number.

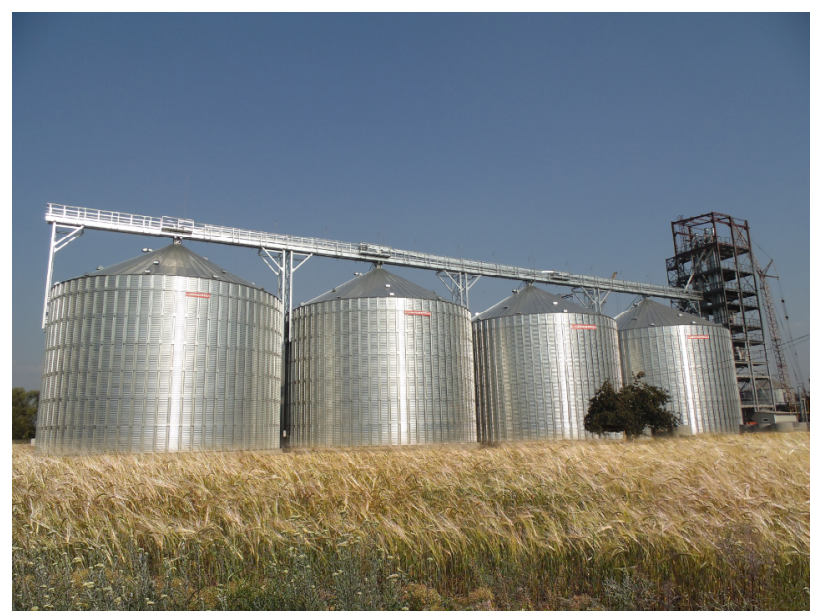

Fig. 2. Arrangement of silos in a row at the warehouse of the enterprise.

In total, we have examined a sample of two, three and four silos with equal and various distances between. The position of each silo was expressed parametrically along two axes (Fig. 4). The size was expressed by the ratio of the peculiar distance between the centres of the cross sections of the silos to their diameter.
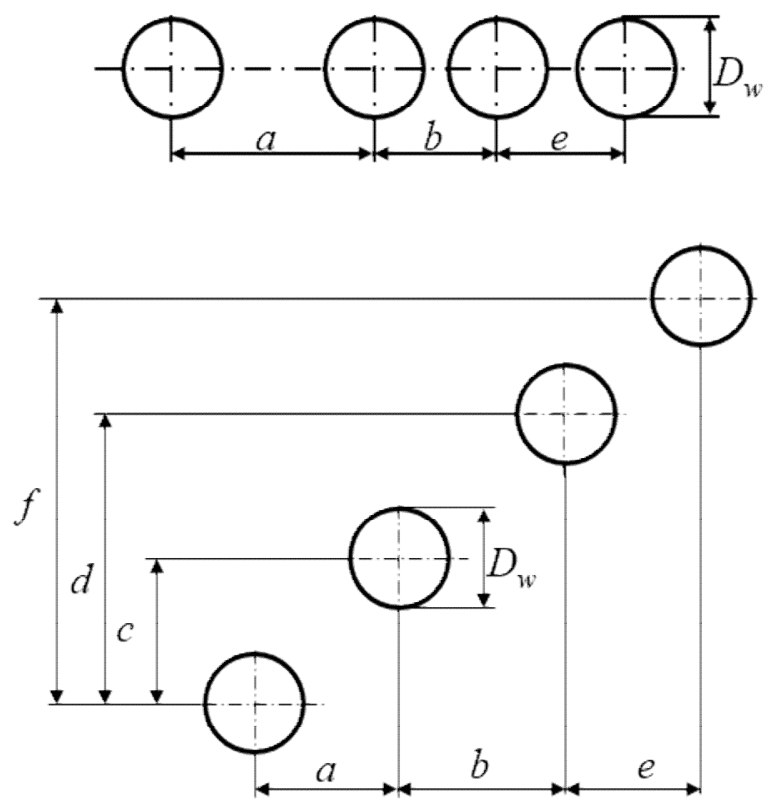

Fig. 4. Examples of silos layouts.

The results showed significant differences in the behavior of three-dimensional flow in near of silos at different initial data. For example, Fig. 5 shows wind flow isosurface for a variant of three silos with different initial data.

For all above considered options we have obtained wind pressure curves for each of the silos. For example, Fig. 6 shows a curve of changes in aerodynamic coefficients for two silos, located one after another.

Another experimental variable was the coefficient of $\operatorname{drag} \mathrm{C}$, the value of which was also found for all the schemes considered in the modelling process. A part of obtained results is summarized in table 2 .

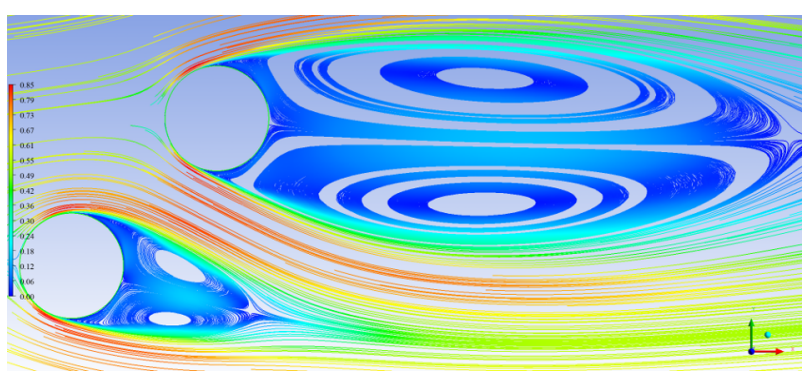

Fig. 5. Visualization of the flow around two silos.

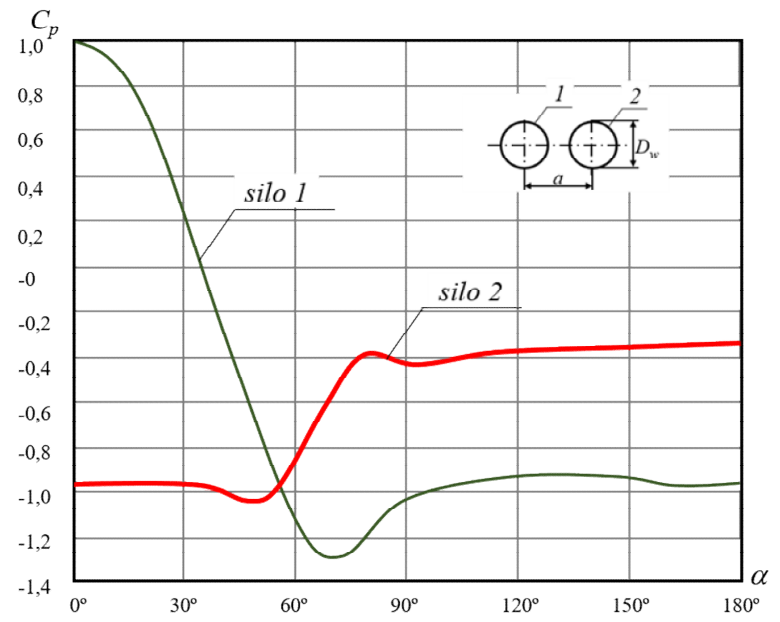

Fig. 6. The graph of variance in aerodynamic coefficients for two silos, located in succession.

Table 2. Coefficients of drag of silos.

\begin{tabular}{|c|c|c|c|c|c|c|}
\hline \multicolumn{3}{|c|}{$\begin{array}{c}\text { Distance } \\
\text { parameter }\end{array}$} & \multicolumn{4}{|c|}{ Coefficients of drag } \\
\hline \multicolumn{7}{|c|}{ Two streamwise silos } \\
\hline \multicolumn{3}{|c|}{$a / D_{w}$} & \multicolumn{2}{|c|}{$C_{l}$} & \multicolumn{2}{|c|}{$C_{2}$} \\
\hline \multicolumn{3}{|c|}{1,4} & \multicolumn{2}{|c|}{0,989} & \multicolumn{2}{|c|}{$-0,526$} \\
\hline \multicolumn{3}{|c|}{2,0} & \multicolumn{2}{|c|}{0,903} & \multicolumn{2}{|c|}{$-0,406$} \\
\hline \multicolumn{3}{|c|}{3,0} & \multicolumn{2}{|c|}{0,841} & \multicolumn{2}{|c|}{$-0,169$} \\
\hline \multicolumn{7}{|c|}{ Three spanwise silos } \\
\hline \multicolumn{2}{|l|}{$c / D_{w}$} & $d / D_{w}$ & $C_{1}$ & \multicolumn{2}{|c|}{$C_{2}$} & $C_{3}$ \\
\hline \multicolumn{2}{|l|}{1,1} & 2,2 & 1,492 & \multicolumn{2}{|c|}{2,256} & 1,492 \\
\hline \multicolumn{2}{|l|}{1,6} & 3,2 & 1,302 & \multicolumn{2}{|c|}{1,883} & 1,291 \\
\hline \multicolumn{2}{|l|}{2,0} & 4,0 & 1,241 & \multicolumn{2}{|c|}{1,586} & 1,236 \\
\hline \multicolumn{7}{|c|}{ Four streamwise silos } \\
\hline$\frac{a}{D_{w}}$ & $\frac{b}{D_{w}}$ & $\frac{e}{D_{w}}$ & $C_{1}$ & $C_{2}$ & $C_{3}$ & $C_{4}$ \\
\hline 1,1 & 1,1 & 1,1 & 0,98 & $-0,59$ & 0,04 & 0,09 \\
\hline 1,4 & 1,4 & 1,4 & 0,95 & $-0,59$ & 0,09 & 0,11 \\
\hline 2,0 & 2,0 & 2,0 & 0,86 & $-0,5$ & 0,16 & 0,16 \\
\hline
\end{tabular}

3D modelling is often used when it is necessary to describe in full the actual building in near of the storage capacity. However, this causes big problems, as the development of detailed models of the silo park, taking 
into account the surrounding buildings and relief, is quite difficult and the calculation itself is time consuming.

This technique is also based on the construction of the optimal ratio of the parametric computational grid, the selection of turbulence models and special computational algorithms. In the interest of time, it is advisable, in the first instance, to perform a computation of a simplified two-dimensional model of a silo or a silo park. This would enable taking a tentative assessment of the design pressures on the body and conical roof of the silo in the park and subsequent generating threedimensional loads based on the results of 2D-calculation.

Special macros and software modules should be used for fast and accurate calculations. This allows us to combine the necessary calculation procedures and to simplify them.

Based on the obtained results of modeling of any type, it is possible to determine the most dangerous wind directions, perform a preliminary assessment of the calculated loads and export loads to the strength analysis program.

\subsection{Results}

The nature of the placement of silos and the distance between them greatly affect the distribution of pressure on their surface. The result differs from those indicators that are taken for single structures and declared in the design standards.

For paired silos, modelling was carried out for various options with a stepwise increase in the distance between centres $a$ from $1,1 D_{w}$ to $10 D_{w}$.

The formation of symmetrical stationary vortices of different elongation and shape was observed in the pattern of distribution of isosurface of closely spaced silos. These symmetrical stationary vortices are located near the leeward side of each of the flow bodies. Behind the first cylinder, two oversize side vortices and two middle vortices, which practically disappear at $a=1,6 D_{w}$, are clearly visible. With regard to the second cylinder, the classic formation of two elongated stable vortices is observed (Fig. 7).

An increase in the distance between the silos leads to the narrowing of the eddy zone, and at $a / D_{w}>3,5$ they form a narrow isthmus with separation.

The graph of variance of the pressure coefficient for the first cylinder takes the typical shape. However, the aerodynamic coefficient curve for the second silo is completely in the negative zone. The value of the aerodynamic coefficient at an angular coordinate of $0^{\circ}$ is $C_{p}=-0,98$ at $a / D_{w}=1,1$. Subsequently, the values beyond the surface of the cylinder decrease very slowly, reaching a minimum at $50^{\circ} \quad C_{p}=-1,05$ (the zone of medium vortices silo 1 ), and then increases more sharply at $45^{\circ}-80^{\circ}$ with the maximum $C_{p}=-0,38$ (the zone of lateral vortices silo 1 ).

After this point, the influence on the aerodynamic coefficient is exerted by the own eddy zones of the silo
2. With further increase in size between the models, the effect of silo zone 1 predictably decreases.

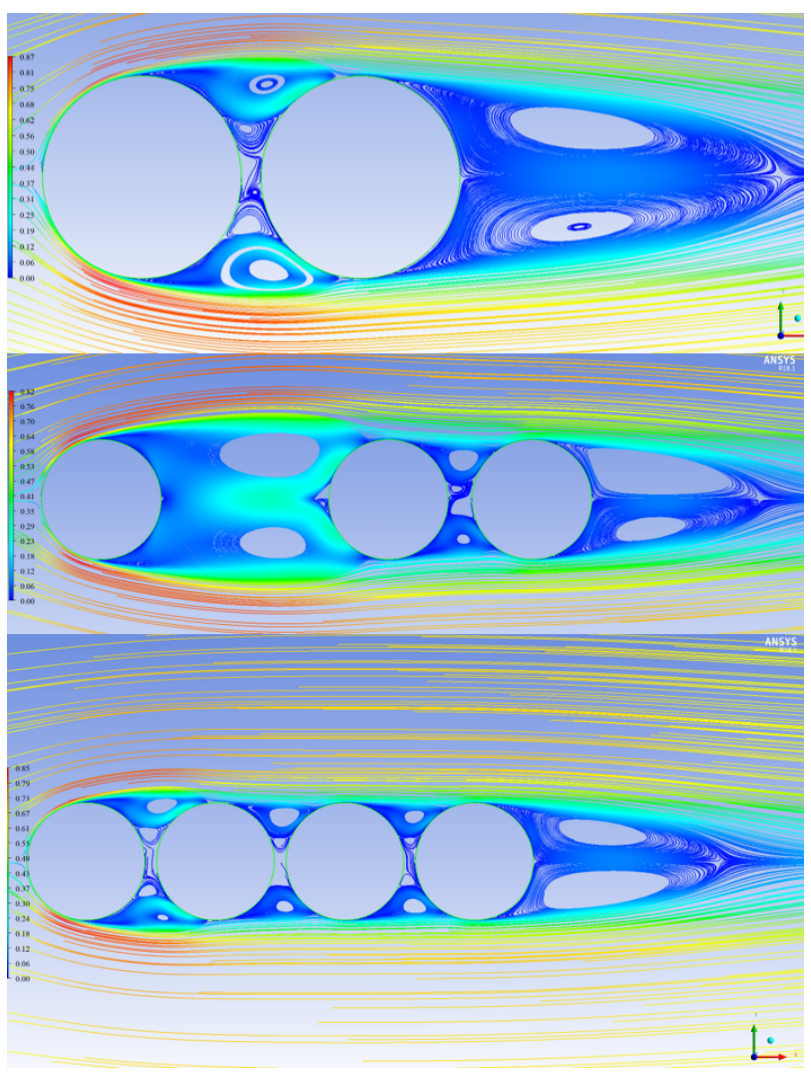

Fig. 7. Simulation of wind action on a system of silos, located in succession.

As the distance increases, the drag coefficients of silo 1 change within $19 \%$, and for silo 2 they change doubly.

For a group of three and four cylinders in series, the flow pattern is similar. For silo 3, the graph of variance of aerodynamic coefficient is also in the negative zone. This is caused by the windy patch from silo 2 . Quantitative values change slightly. For the distance $b / D_{w}=1,2$, there is one maximum at $50^{\circ}\left(C_{p}=-0,1\right)$ and one minimum at $95^{\circ}\left(C_{p}=-0,42\right)$. At the distance of $a / D_{w}=5$, the graphs $C_{p}$ of silo 1 and silo 2 converge.

Graphs of variance of aerodynamic coefficients for silos placed in a group of four bodies can be projected (Fig. 8). Quantitative characteristics do not exceed the values for the groups of three bodies.

The instantaneous blowing pattern for the case of different direction of the wind flow is shown in Fig. 9. To simulate the flow, at first two silos were selected with the distance between the centres of $0,2 D_{w}$, which was then increased. The visualization shows how a bevelled flow zone with high velocities is formed. The eddy zone of one silo is longer and has an asymmetry in the area close to the second silo. For the second silo, the eddy zone is smaller and develops sideways. Such nature of the flow causes combination of the stall points and zones of maximum pressure. 


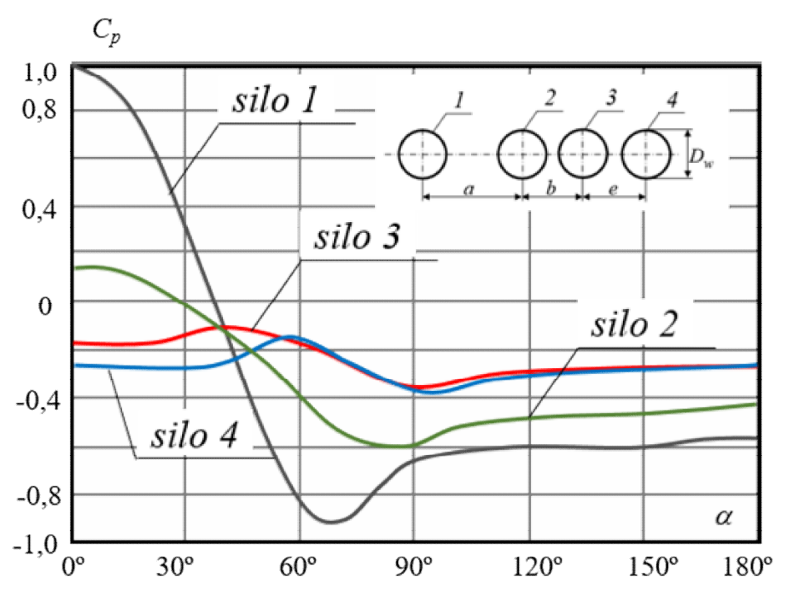

Fig. 8. Simulation $a / D_{w}=e / D_{w}=5,0, b / D_{w}=1,2$.

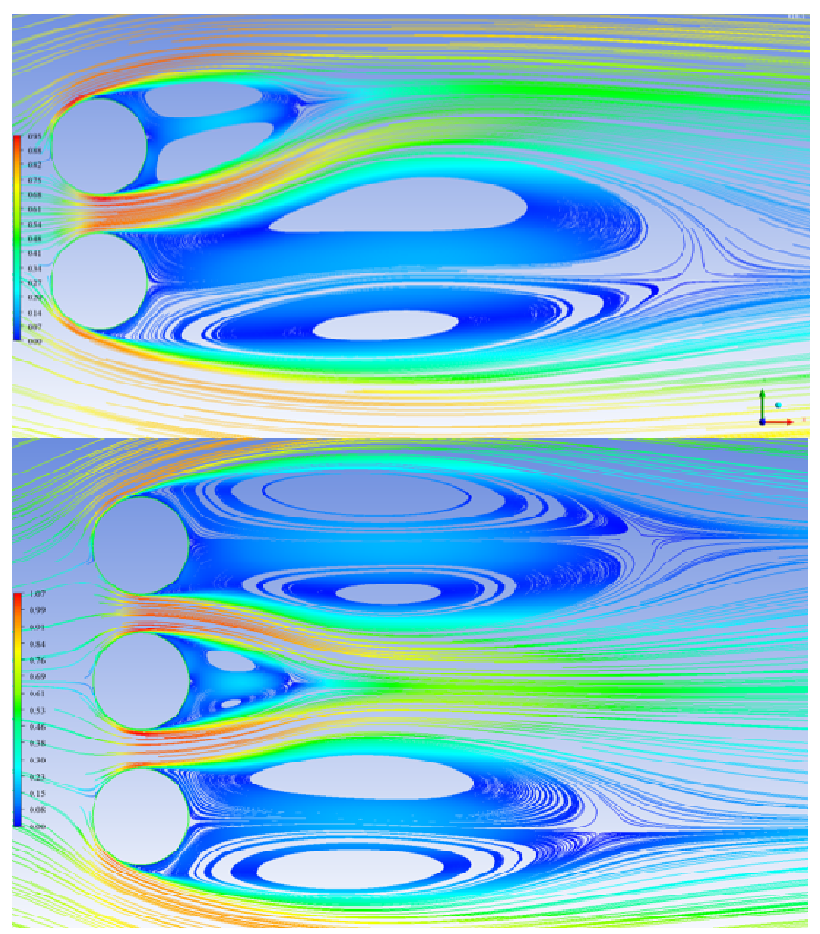

Fig. 9. Simulation of wind action on the system of parallel silos.

At $c / D_{w}=1,1$ the value of aerodynamic coefficients of the upper silo, which has smaller eddy zone, up to $25 \%$, is greater than the corresponding indicators of the neighbouring silo. With increasing distances between the silos, this difference is less noticeable. At $c / D_{w}=2,5$ the graphs of the opposite parts are almost convergent, and at $c / D_{w}=3,5$ they coincide. This indicates that there is no screening effect.

When three cylindrical bodies are placed in parallel, the specific formation of two huge vortices is observed in the windward area of the middle silo. Between the vortices there arise symmetrical flows, the air velocity in which reaches maximum values.

At the distance of $>2,5 D_{w}$, three independent flow regions are formed around each silo. For the aerodynamic coefficient, such an arrangement of the containers causes the following changes. With an equal distance between the centres of the silos, the middle silo has a symmetrical graph $C_{p}$.

At the minimum point, it reaches the values of $C_{p}=-1,7 \ldots-1,95$ at the distance between the centres $1,1 D_{w}-1,2 D_{w}$, and at the distance of $c / D_{w}=1,4$; $d / D_{w}=2,8$ the minimum value of $C_{p}=-2,3$ is reached. For outer silos, the graphs are asymmetric for the upper and bottom surfaces.

With a very close arrangement of the silos (up to $\left.1,4 D_{w}\right)$, a negative minimum of $C_{p}=-2,38$ is reached at around $100^{\circ}$. At the distances of $>1,6 D_{w}$, the graphs of aerodynamic coefficients are smoothed and drawn closer together.

A variant of simulation with diagonal arrangement of silos is shown in Fig. 10.

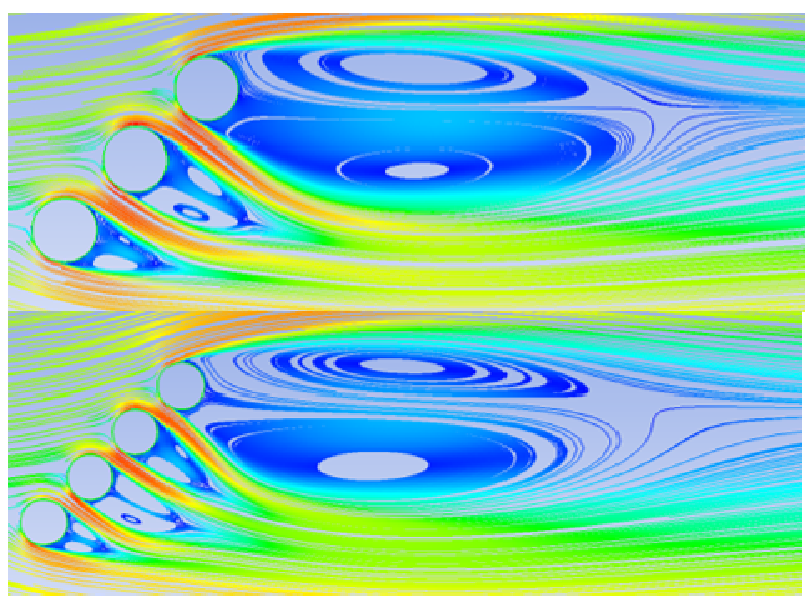

Fig. 10. Simulation of wind action on the system of diagonally located silos.

The position of the silos was regulated by the given values of the distances $a / D_{w}, c / D_{w}$ (for two silos). The picture of the eddy zone changes. There is clear deviation of the isolines into the lateral side between the flow objects. As in the previous blows, two vortices are formed behind each of the cylinders in the windward zone; however, they are different in size and for the first object they are distinguished with discernable asymmetry and lateral direction. For the second silo, which is located more remotely, the asymmetry of paired vortices is practically indiscernible. The total length of the wake boundary is four times greater.

The distribution curve of aerodynamic coefficients also lacks symmetry. For the first silo the difference in zero points of the aerodynamic coefficient on the lateral surfaces is $15^{\circ}$, while for the second silo it is only $6^{\circ}$. At $a / D_{w}=c / D_{w}=1,1$, the maximum values of the aerodynamic coefficient are within $C_{p}=-1,1 \ldots-1,16$, at $a / D_{w}=1,2, c / D_{w}=2$, they grow to $C_{p}=-1,15 \ldots 1,27$, at $c=3 D_{w}$ they practically do not change $C_{p}=-1,18 \ldots-1,25$. The shape of pressure distribution graphs for three silos is asymmetrical in its upper and 
lower parts. It should be noted that angular displacement along the contour is caused by various stall points. Quantitatively, $t$ aerodynamic coefficients are large. For the distances of $1,1 D_{w}$ between the centres, the minimum aerodynamic coefficient of the middle cylinder is $C_{p}=-1,55$, for the most distant silo it is $C_{p}=-1,40$ and it will be $C_{p}=-1,38$ for the nearest one. At a distance, the minimums of silo 1 and silo 2 reach $C_{p}=-1,5$.

Development of the flow for a row of four silos is similar. It is characterized by the presence of two largescale concentrated vortices behind silo 4 and curved eddy zones for the rest silos. At a distance of $1,0 D_{w}$ in both directions, the maximum values of the aerodynamic coefficient were in silo $3-C_{p}=-1,38 \ldots \ldots .1,5$, with the increase to $2,5 D_{w}$ for silo $3-C_{p}=-1,3$. For other silos, the values did not exceed this value.

\section{Conclusion}

1. In computer modelling of the wind action on silos, it was found that the value of the aerodynamic characteristics (pressure, drag and lift coefficients) of experimental models depend heavily on the appropriateness of the taken turbulence model and on the quality of the computational meshes.

2. Based on the carried out verification tests, a special technique was developed for constructing finite element meshes for the tasks of modelling wind action on silos.

3. Simulation of two-dimensional and threedimensional flow around simple silo parks at high Reynolds numbers has been performed.

4. Based on the results, the studying of the kinematic spectrum and interferential interaction of models of groups of two, three and four silos (400 variants of blowing) were carried out at various angles of attack of the wind current within the framework of 2D modelling.

5. We have obtained wind pressure curves for each of the cylindrical bodies in the group for different initial conditions. The analysis of their values has also been carried out in this academic research.

6. It has been discovered that wind actions on a silo in a silo park can significantly exceed the action on a separate silo.

\section{References}

1. Loads and influences. DBN V.1.2.-2:2006 (Kyiv, 2006), p. 60

2. Wind Design Guidelines (Stroiisdat, Moscow, 1978), p. 210

3. Actions on structures. General actions. Wind actions Eurocode 1. EN 1991-1-4:2005 (CEN, Belgium, 2010), p. 155

4. Minimum Design Loads for Buildings and Other Structures. ASCE 7-10. (ASCE, 2017), p. 822
5. National Building Code of Canada. NBC:2015. (National Research Council of Canada. Canadian Commission on Building and Fire Codes Canada, 2015), p. 696

6. E.V. Gorokhov, S.G. Kuznetsov, Eksperimentalnye metody opredeleniia vetrovykh nagruzok na zdaniia $i$ sooruzheniia (Experimental methods for determining wind loads on buildings and structures) (Nord-press, Donetsk, 2009)

7. A. Flaga, Eksperymentalne wspomaganie projektowania przy wptywach środowiskowych na budowle $i$ ludzi (Experimental design aiding in environmental influences on buildings and people) (Pawe, Krakow, 2011)

8. M.M. Zdravkovich, Flow Around Circular Cylinders (Oxford Science Publications, Oxford, 1997)

9. Q. Zhang, V.M. Puri, H.B. Manbeck, Model for frictional behavior of wheat on structural materials. Trans ASAE 31 (3), 898-903 (1988)

10. O. Lapenko, A. Makhinko, N. Makhinko, Features of silos calculations at asymetric wind load by using momentless theory. Tehnički glasnik 13 (1), 12-15 (2019)

11. M.A. Berezin, V.V. Katyushin, Atlas aerodinamicheskikh kharakteristik stroitelnykh konstruktsii (Atlas of aerodynamic characteristics of building structures) (Olden-poligrafiia, Novosibirsk, 2001)

12. E.I. Retter, Arkhitekturno-stroitelnaia aerodinamika (Architectural and construction aerodynamics) (Stroiisdat, Moscow, 1984)

13. I.IU. Grafskii, M.I. Kazakevich, Aerodinamika plokhoobtekaemykh tel (Aerodynamics of poorly streamlined bodies) (DGU, Dnipropetrovsk, 1983)

14. M.M. Zdravkovich, The effects of interference between circular cylinders in cross flow. Journal of Fluids and Structures 1 (2), 239-261 (1987)

15. R.I. Kinash, O.Ye. Kopylov, Aerodynamichni doslidzhennia chotyrokh kolovykh tsylindriv. Bulletin of the National University Lviv Polytechnic 495, 88-92 (2004)

16. N.O. Makhinko, Dissertation, Odessa State Academy of Civil Engineering and Architecture, 2020

17. B. Cantwell, D. Coles, An experimental study of entrainment and transport in the turbulent near wake of a circular cylinder. J. Fluid Mech, 136 (1983)

18. A. Roshko, Experiments on the flow past a circular cylinder at very high Reynolds numbers. J. Fluid Mech 10 (3), 345-356, (1961)

19. J.W.J. Van Nuen, Pressure and forces on a circular cylinder in a cross flow at high Reynolds numbers. Flow Induced Structural Vibrations, 748-754 (1974) 